the isolation of bacteria from clinical specimens. In: Balows A, Hausler WV Jr, Herrmann KL, Isenberg HD, Shadomy HS, eds. $M$ anual of Clinical Microbiology. 5th ed. Washington, DC: American Society of Microbiology; 1991.

15. McGeer A, Campbell B, Emori TG, et al. Definitions of infection for surveillance in long-term care facilities. A m J Infect Control 1991:19:1-7.

16. Leibowitz HM, Pratt MV, Flagstad IJ, Berrospi AR, Kundsin R. Human conjunctivitis 1. Diagnostic evaluation. Arch Ophthalmol 1976;94:1747-1749

17. Seal DV, Barrett SF: McGill JI. Aetiology and treatment of acute bacterial infectionofthe externaleye. Br J O pthal mol 1982;66:357360 .

18. Garner JS, Jarvis WR, Emori TG, Horan TC, Hughes JM. CDC definitions for nosocomial infection, 1988. Am J Infect Control 1988:16:128-140.

19. Ruben FL, Norden CW, Heisler B, Korica Y. An outbreak of Streptococcus pyogenes infections in a nursing home. Ann Intern Med 1984;101:494-496.

20. McNutt L-A, Casiano-Colon AE, Coles FB, et al. Two outbreaks of primarily noninvasive group A streptococcal disease in the same nursing home, New York, 1991. Infect Control Hosp Epidemiol 1992;13:748-751.

21. Brennen C, Muder R. Conjunctivitis associated with methicillinresistant Staphylococcus aureus in a long-term care facility. Am J M ed 1990;88(suppl 5):14N-17N.

\title{
HIV Testing of Inpatients Not Cost-Effective in Preventing HIV Infections of Healthcare Workers
}

\section{by Gina Pugliese, RN, MS Medical News Editor}

In 1993, the CDC expanded its guidelines for HIV testing by recommending not only that healthcare workers (HCWs) routinely assess HIV risk and offer testing and counseling to high-risk patients but also that all hospitals with an HIV seroprevalence rate of at least $1 \%$ (or an AIDS diagnosis rate of 1 case per 1,000 discharges) routinely offer voluntary counseling and HIV testing to all patients aged 15 to 54 years. Further, the CDC recommended that these services be structured to facilitate confidential, voluntary patient participation and should include pretest information about the testing procedures, appropriate post-test counseling for infected patients and those at increased risk, and referral of HIV-infected persons for medical evaluation (Morbidity and M ortality Weekly Report; March 5, 1993).

Dr. Peter Lurie of the University of California, San Francisco, and colleagues recently reported the findings of a study on cost-effectiveness of voluntary counseling and testing of hospital inpatients for HIV infection.
The study found no justification for testing inpatients to prevent HIV infection of healthcare workers (HCWs). However, screening of inpatients to detect HIV infection to provide early counseling and treatment may be justified at seroprevalences exceeding $1 \%$, but issues of medical or social discrimination, false-positive results, informed consent, and logistics must be resolved first.

Using data from studies of costeffectiveness of HIV testing from literature and consultation with experts, the authors developed decision analysis models to evaluate the costeffectiveness of HIV testing. Testing to avert HCW infection may prevent 3.6 $\mathrm{HIV}$ infections per year nationwide at a total program cost of $\$ 2.7$ billion, or a cost of $\$ 753$ million per HCW infection averted per year.

At baseline assumption (seroprevalence $=1 \%$ ), testing to detect inpatient HIV infection was determined to cost $\$ 16,104$ per year per infection detected. Cost-effectiveness at baseline improves to $\$ 8,353$ per HIV infection detected if the seroprevalence is $10 \%$. If testing is limited to hospitals with inpatient seroprevalence of at least $1 \%$, approximately 5,400 persons per year will be falsely labeled HIVpositive. If testing is implemented at all US hospitals, at a baseline seroprevalence of $1 \%$ and with an HIV test specificity of $0.9999,30,919$ patients will be falsely positive in the first year.

The authors note that any decision to implement a policy to counsel and test millions of inpatients also must consider carefully whether hospitals, particularly those with high HIV seroprevalences, are capable of adequately executing such a laborintensive program. The authors conclude that many difficult policy questions remain: Will infected persons detected in the program experience medical or social discrimination? Can the problem of false-positive or indeterminate test results be reduced to an acceptable level? How will counseling and testing be offered to sick patients who may not be able to give truly informed consent or to understand test results? Is an inpatient counseling and testing program the best use of scarce HIV prevention resources?

FROM: Lurie P, Avins AL, Phillips $\mathrm{KA}$, et al. The cost effectiveness of voluntary counseling and testing of hospital inpatients for HIV infection. JAMA 1994;272:1832-1838. 